\title{
Textile-Based Antenna using Aperture-Coupled Technique for Global Positioning System (GPS) Application
}

\author{
${ }^{* 1}$ A.F.M. Pazil, ${ }^{2}$ N.H. Abd. Rahman, ${ }^{3}$ N.A. Ramli, ${ }^{4}$ N.F.H.A. Razak \\ ${ }^{1,3,4}$ Centre of Advanced Electrical \& Electronic System, Faculty of Engineering, \\ Built Environment \& IT, SEGi University \\ ${ }^{2}$ Antenna Research Centre, Faculty of Electrical Engineering, \\ Universiti Teknologi MARA \\ *anis@ segi.edu.my
}

\begin{abstract}
This paper presents a preliminary design of a textile antenna using aperturecoupled technique for Global Positioning System (GPS) application. Mostly used in wearable application, textile materials are suitable to be applied as the antenna substrates due to the flexibility and conformability characteristic. In this paper, felt material with the relative permittivity, $\varepsilon_{\mathrm{r} 1}$ of 0.76 and thickness of $2.69 \mathrm{~mm}$ is chosen as the substrate, and is attached to a pure copper layer as the conductive material with the thickness of $0.07 \mathrm{~mm}$. Meanwhile, the textile material used as the feed substrate is fleece with the thickness of $0.69 \mathrm{~mm}$ with the relative permittivity $\varepsilon_{\mathrm{r} 2}$ of 0.91 . The design procedure is discussed and the simulated data using the CST Microwave Studio software is further analysed in terms of the return loss, gain, directivity and radiation pattern.
\end{abstract}

Keywords: Textile Antenna, Aperture-Coupled, GPS, Felt, Fleece

\section{Introduction}

Recent development in body-worn applications have shown a growing interest towards wearable antenna. With the emergence of 5G technology, this body-worn application has firmly placed its demand in the field of healthcare monitoring, navigation, military etc. Wearable antenna should demonstrates lightweight and flexible properties while providing comfort to the wearer. From this perspective, 
textile antenna renders a good characteristic of wearable application as it is made up of full or partial fabric material as compared to the conventional rigid antenna (Potey \& Tuckley, 2018). Textile antenna has merits in the body-worn applications due to the robustness, low maintenance and easy to integrate with clothing. In addition, the design simplicity of the antenna has an added advantage (Agbor, Biswas \& Mahbub, 2018) to which it provides greater potential due to its inexpensive cost in development.

However, the performance of the conventional microstrip antenna will experience the degradation in terms of bandwidth, reflection coefficient and performance efficiency due to the spurious radiation effect resulted from the feeding network. This effect is prominent as there is no shielding between the radiator and the feeding network (Kumar, Kaur \& Singh, 2013). Therefore, the application antenna structure using the aperture-coupled feeding technique is favourable because of the isolation between radiator and the feed network that constitutes to a wider bandwidth and better return loss by optimising the length and width of aperture size (Chandravanshi et al., 2015).

The usage of textile materials as substrates in antenna design also provides justifications in determining the efficiency and bandwidth based on the thickness and dielectric constant of selected material (Manwal et al., 2016). Due to the narrow range of the permittivity values of textile materials, the thickness of the materials will mainly determine the bandwidth, input impedance and frequency of resonance for a fixed permittivity (Dhupkariya, Singh \& Shukla, 2015). Nevertheless, the choices of the thickness of the dielectric material is a compromise between efficiency and bandwidth of the antenna.

In this work, felt and fleece fabrics are used as the substrates for the antenna due to the hydrophobic properties of both. This property is an important factor for consideration in wearable application since it contributes to less absorbency factor of moisture, which will affect the antenna performance. This paper presents the design of the textile antenna using the different thickness for two non-identical substrates with the aperture-coupled feeding network. The optimised design is presented and further analyse in terms of operating frequency, gain, bandwidth, and the return loss characteristics for the desired performance at GPS application. 


\section{Materials selection criteria}

In this study, two types of textile materials that represent the antenna substrate and feed substrate are used in the structure. The use of two-layer antenna structure with different thickness will affect the bandwidth and coupling level which provides an option to optimise the antenna performance due to the difference of characteristics imposed (Vallozzi et al, 2007). A thicker substrate will result in a wider bandwidth but less coupling for a given aperture size. Felt material is chosen to be the antenna substrate due to its greater thickness which provides an adequate bandwidth. The feed substrate used in this study is fleece material that is much thinner to restrict the radiation losses. Table 1 shows the features of the textile materials used in this paper.

Table 1. Features of textile materials

\begin{tabular}{lccc} 
Material & $\begin{array}{r}\text { Thickness, } \\
\mathbf{m m}\end{array}$ & $\begin{array}{r}\text { Permittivity, } \\
\boldsymbol{\varepsilon}_{\mathbf{r}}\end{array}$ & $\begin{array}{c}\text { Tangent Loss, } \\
\text { Felt }\end{array}$ \\
2.67 & 0.76 & 0.52 \\
\hline Fleece & 0.69 & 0.91 & 0.16
\end{tabular}

\section{Antenna design}

Applying the aperture-coupled design techniques, the copper tape is used as the antenna radiating element, feed line and the ground plane. This is due to its properties that exhibits excellent conductivity and having low corrosion. For this antenna design, the thickness of the copper tape used is $0.07 \mathrm{~mm}$ with the conductivity of $5.96 \times 10^{7}$ $[\mathrm{S} / \mathrm{m}]$.

Figure 1a shows the geometry of the aperture-coupled microstrip antenna (ACMA) in the perspective view while Figure 1b is in the side view. The overall structure consists of five layers with the feed line at the bottom-most layer of this structure, which is attached to the feed substrate of the felt textile. The ground plane is the centre layer of this structure whereby the aperture slot lies to couple the power in the microstrip feed line to the radiating patch of the antenna. In order to have a maximum coupling, the feed line should be positioned at the right angles to the center of the slot. To achieve good performance, the position of the radiating patch must also 
be centered over the slot whereby skewing the radiating patch off the centre will result in decrease of coupling level (Pozar, 1996).

The slot length also affects the coupling level and the back radiation. Therefore, the proposed ratio of slot length to width is typically $1 / 10$. In this antenna design, the proposed ratio is met by adopting the width $=4 \mathrm{~mm}$ and the length $=41 \mathrm{~mm}$. To achieve the characteristic impedance of $50 \Omega$ at the desired frequency of $1.575 \mathrm{GHz}$, the microstrip feed line requires a width of $4.5 \mathrm{~mm}$. This feed line width can strongly couple to the antenna patch via the slot by keeping it thinner at certain degree as shown in Table 2.

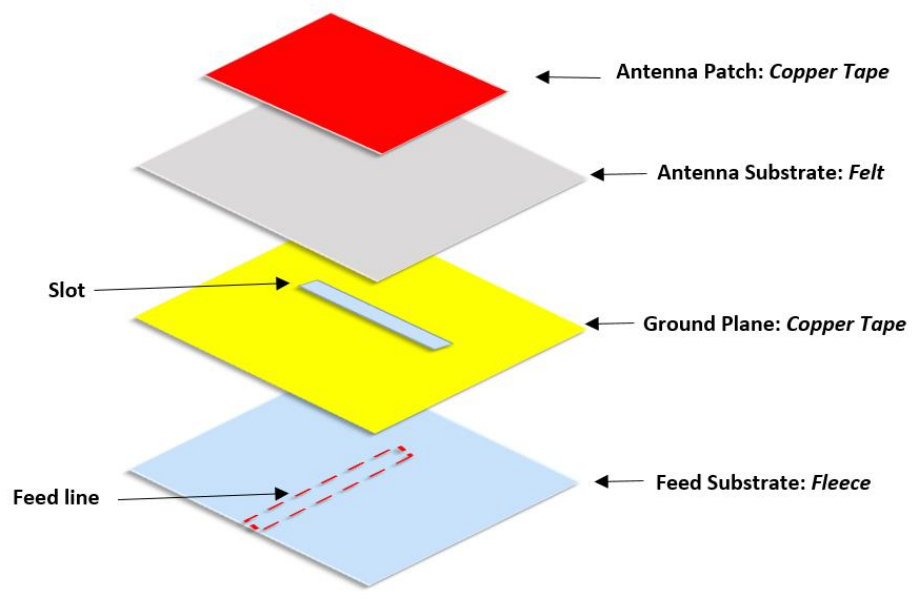

(a)

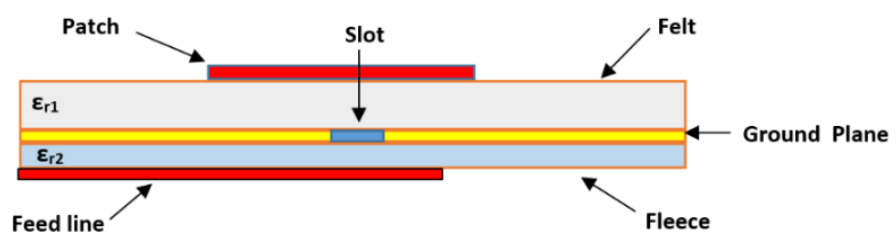

(b) 


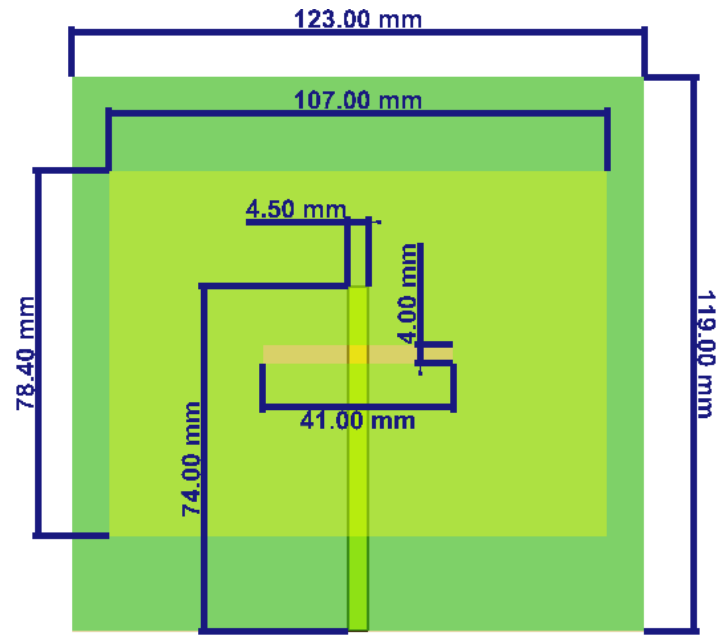

(c)

Figure 1. Geometry of antenna dimension (a) Perspective View (b) Side View (c) Top View

The dimensions of the optimised design for ACMA is summarized in Table 2.

Table 2. Summary dimensions for the optimised antenna design

\begin{tabular}{|c|c|c|c|}
\hline \multirow[b]{2}{*}{ Properties } & \multicolumn{3}{|c|}{ Parameters } \\
\hline & $h(\mathrm{~mm})$ & $W(\mathrm{~mm})$ & $L(\mathrm{~mm})$ \\
\hline \multirow{2}{*}{$\begin{array}{l}\text { Patch } \\
\text { Copper Tape }\end{array}$} & 0.07 & 107.0 & 78.4 \\
\hline & & & \\
\hline \multirow{2}{*}{$\begin{array}{l}\text { Antenna Substrate } \\
\text { Felt }\end{array}$} & 2.67 & 123.0 & 119.0 \\
\hline & & & \\
\hline $\begin{array}{l}\text { Ground Plane } \\
\text { Copper Tape }\end{array}$ & 0.07 & 123.0 & 119.0 \\
\hline $\begin{array}{l}\text { Feed Substrate } \\
\text { Fleece }\end{array}$ & 0.69 & 123.0 & 119.0 \\
\hline \multirow{2}{*}{$\begin{array}{l}\text { Microstrip Feedline } \\
\text { Copper Tape }\end{array}$} & \multicolumn{2}{|c|}{$W(m m)$} & $L(m m)$ \\
\hline & \multicolumn{2}{|c|}{4.5} & 74 \\
\hline \multirow[t]{2}{*}{ Slot } & \multicolumn{2}{|c|}{$W(m m)$} & $L(m m)$ \\
\hline & \multicolumn{2}{|c|}{4} & 41 \\
\hline
\end{tabular}

\section{Result and discussion}

The optimised simulated result of the reflection coefficient is depicted in Figure 2. The antenna resonates at $1.575 \mathrm{GHz}$ with the magnitude of reflection coefficient (S11) is $-19.48 \mathrm{~dB}$ and the achieved bandwidth is from $1.5559-1.5947 \mathrm{GHz}$. This 
bandwidth has covered $76 \%$ of the operating bandwidth for the navigation signal of Global Navigation Satellite System (GNSS) which is allocated at the frequency band of $1.559-1.610 \mathrm{GHz}$ (Hassan \& Attiya, 2018)

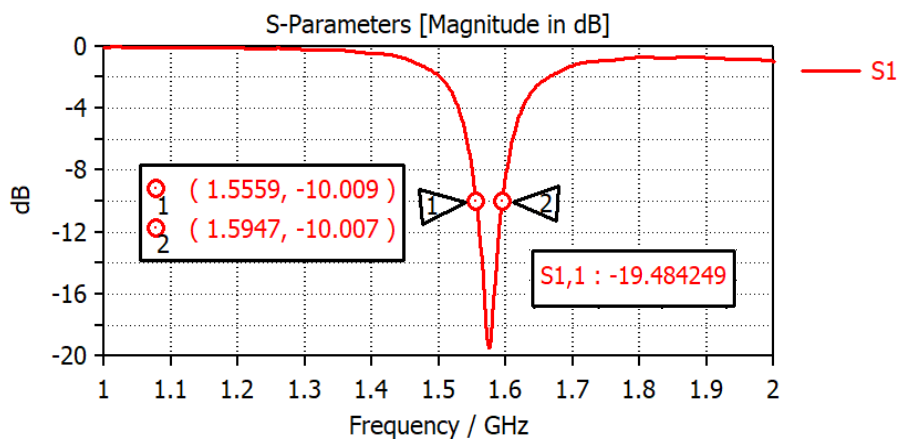

Figure 2. Return loss $\left(\mathrm{S}_{11}\right)$ of simulated antenna

The result of the directivity and radiation pattern of the simulated antenna have been analysed in this section. As observed in Figure 3, the directivity of this antenna is $8.48 \mathrm{dBi}$ with its gain achieving up to $8.19 \mathrm{~dB}$ at the resonant frequency of 1.575 GHz. The high gain achieved is mainly due to the thin rectangular slot used as this type of design provides stronger coupling to the patch.

The simulated $\mathrm{E}$ and $\mathrm{H}$-plane far-field radiation pattern at the resonant frequency are presented in Figure 4. The radiation pattern depicted that the front-to-back ratio of this antenna is performed at $20.49 \mathrm{~dB}$ with the yielded efficiency of $96.19 \%$. Such value is considered as a good value of antenna performance, which resulted from less spurious radiation in the back region and subsequently improved the efficiency of antenna. 


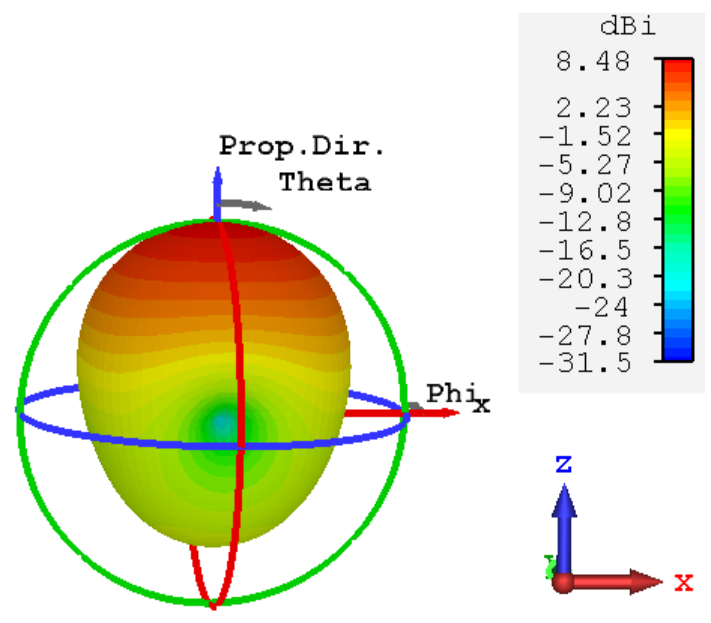

Figure 3. Gain plot of the simulated antenna

Farfield Gain Abs (Phi=90)

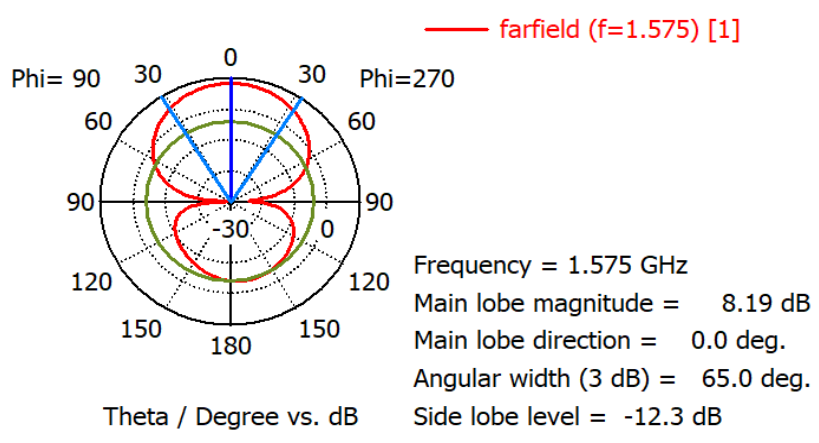

(a) 


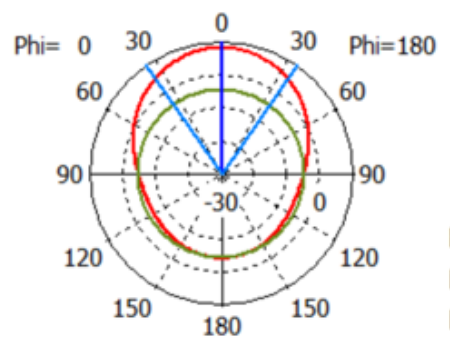

Theta / Degree vs. dB

\section{Frequency $=1.575 \mathrm{GHz}$ \\ Main lobe magnitude $=8.19 \mathrm{~dB}$ \\ Main lobe direction $=0.0 \mathrm{deg}$. \\ Angular width $(3 \mathrm{~dB})=69.4 \mathrm{deg}$.}

Side lobe level $=-12.7 \mathrm{~dB}$

(b)

Figure 4. Radiation pattern of the simulated antenna (a) $H$ - plane $\left(\mathrm{Phi}=90^{\circ}\right)\left(\right.$ b) $E$ - plane $\left(\mathrm{Phi}=0^{\circ}\right)$

\section{Conclusion}

In this paper, the performance of microstrip rectangular patch antenna by implementing aperture-coupled technique has been investigated. It has been demonstrated by the simulated result that this technique is able to achieve a high realised gain at $8.144 \mathrm{~dB}$. Based on the simulated result discussed, it can be concluded that it is necessary to choose a range of substrates that will be able to ensure great efficiency, high bandwidth and good radiation in the wearable textile application. Other than that, the substrate selected for the feed network must possess higher permittivity than the patch substrate for a maximum antenna performance. The proposed wearable textile antenna has a potential to be integrated into the clothing and subsequently realise in the GPS application.

\section{References}

Potey, P.M. and Tuckley, K. (2018) "Design of wearable textile antenna with various substrate and investigation on fabric selection," 2018 3rd Int. Conf. Microw. Photonics, ICMAP 2018, vol. 2018-January, no. Icmap, pp. 1-2.

Agbor, I., Biswas, D.K. and Mahbub, I. (2018) “A comprehensive analysis of various electro-textile materials for wearable antenna applications," Proc. 2018 Texas Symp. Wirel. Microw. Circuits Syst. WMCS 2018, pp. 1-4. 
Kumar, A., Kaur, J. and Singh, R. (2013) "Performance Analysis of different feeding techniques,” Int. J. Emerg. Technol. Adv. Eng., vol. 3, no. 3, pp. 884-890, 2013.

Chandravanshi, A. et al. (2015) "Theory and Applications of Applied Electromagnetics: APPEIC 2014," IEEE Trans. Antennas Propag., vol. 344, no. 12, pp. 4490-4496

Manwal, Y., Bisht, S., Kumari, S., Rai, S. and Chauhan, B. (2016) “Literature Review On Wearable Textile Antennas 1,”pp. 35-39.

Dhupkariya, S., Singh, V.K. and Shukla, A. (2015) "A Review of Textile Materials for Wearable Antenna," J Microw. Eng. Technol, vol. 1, no. October, pp. 7-14.

Vallozzi, L., Rogier, H., Hertleer, C., Van Langenhove, L. and Tronquo, A. (2007) "Aperture-Coupled Patch Antenna for Integration Into Wearable Textile Systems," IEEE Antennas Wirel. Propag. Lett., vol. 6, pp. 392-395.

Pozar, D.M. (1996) "A review of aperture coupled microstrip antennas: History, operation, development, and applications," Univ. Massachusetts Amherst, no. May, pp. 1-9.

Hassan, W.M and Attiya, A.M. (2018) "Textile antenna integrated with a cap for L1 GPS application,” Natl. Radio Sci. Conf. NRSC, Proc., vol. 2018-March, no. Nrsc, pp. 38-46. 